\title{
The CPR outcomes of online medical video instruction versus on-scene medical instruction using simulated cardiac arrest stations
}

Chaiyaporn Yuksen ${ }^{1}$, Sorravit Sawatmongkornkul ${ }^{1}$, Jarupol Tuangsirisup ${ }^{1}$, Kittisak Sawanyawisuth ${ }^{2,3}$ and Yuwares Sittichanbuncha ${ }^{*}$

\begin{abstract}
Background: Non-traumatic cardiac arrest is a fatal emergency condition. Its survival rate and outcomes may be better with quick and effective cardiopulmonary resuscitation (CPR). Telemedicine such as telephone or real time video has been shown to improve chest compression procedures. There are limited data on the effects of telemedicine in cardiac arrest situations in the literature particularly in Asian settings.
\end{abstract}

Methods: This study was conducted by using two simulated cardiac arrest stations during the 2014 annual Thai national conference in emergency medicine. These two stations, nos. 5 and 11, were a part of the conference activity called "EMS rally" which was comprised of 14 stations. Both stations were shockable and out-of-hospital cardiac arrest situations; station 5 was online instructed, while station 11 was on-scene instructed. There were 14 representative teams from each province from all over Thailand who participated in the rally. Each team had one physician, one nurse, and two emergency medicine technicians. Eight CPR outcomes were evaluated and compared between the online versus on-scene situations.

Results: There were 14 representative teams that participated in the study; a total of 14 physicians, 14 nurses, and 28 emergency medicine technicians. The average ages of participants in all three occupations were between the second and third decade of life. The percentages of participants with more than 3 years in ambulance experience was $7.1,64.3$, and $53.6 \%$ in the physicians, nurses, and EMTs groups. The median times of all outcomes were significantly longer in the online group than the on-scene group including times from start to chest compression (total 102 vs $36 \mathrm{~s}$ ), total times from the start to VTNF detection (187 vs 99 s); times from VTNF detection to the first defibrillation (57 vs 28 s); and times from the start of adrenaline injection (282 vs 165 s). The percentages of using amiodarone ( $21.43 \%$ vs $57.14 \%$; $p$ value $<0.001$ ), establishment of a definitive airway ( $35.71 \%$ vs $100 \%$; $p$ value 0.003 ), and correct detections of pulseless electrical activity (PEA) (28.57\% vs $100 \% ; p$ value $<0.001)$ were significantly lower in the online group than the on-scene group. The high quality CPR outcomes between the online group and on-scene group were comparable.

Conclusions: The online medical instruction may have worse CPR outcomes compared with on-scene medical instruction in shockable, simulated CPR scenarios. Further studies are needed to confirm these results.

Keywords: Ventricular tachycardia, Pulseless electrical activity, CPR, Online, On-scene

\footnotetext{
* Correspondence: yuwares.sit@mahidol.ac.th

'Department of Emergency Medicine, Faculty of Medicine, Ramathibodi

Hospital, Mahidol University, Bangkok 10400, Thailand

Full list of author information is available at the end of the article
} 


\section{Background}

Non-traumatic cardiac arrest is a fatal emergency condition [1]. The survival rate of cardiac arrest may increase if it is witnessed and the patient receives basic life support (BLS) within 4 min or advanced cardiac life support (ACLS) within 8 min [2, 3]. Cardiopulmonary resuscitation (CPR) has an aim to have spontaneous cardiac function without post-cardiac arrest brain injury [4]. Both BLS and ACLS including using medications or defibrillations may be needed [4].

CPR can be performed by trained medical personnel or bystanders [4]. A previous study showed that CPR was successfully instructed via telephone [5]. An increase of CPR performance was $11 \%$ after the telephone CPR program was launched; at least four lives were saved [5]. With newer communication technologies, telemedicine such as real time video may be helpful in BLS and chest compression $[6,7]$. The advantage of video instruction is real time feedback [7] although some limitations exist such as poor signals or noise during the communication [6]. Telemedicine is also useful in four emergency events such as drowning, burns, intoxication, or renal colicky pain patients during the pre-hospital period in emergency medical services without physicians [8]. There are, however, limited data on the effects of telemedicine in cardiac arrest situations in the literature particularly in Asian settings.

\section{Methods}

\section{Study design}

This study was a retrospective study. Data were retrieved from the 2014 annual Thai national conference in emergency medicine. Two simulated cardiac arrest stations during the conference were studied. These two stations, stations nos. 5 and 11, were a part of the conference activity called "EMS rally" which was comprised of 14 stations. Both of these stations were shockable and outof-hospital cardiac arrest situations. Station no. 5 was an online instructed station, while station no. 11 was an onscene station. All teams performed all 14 stations of the rally blinded to others including both online and on-scene instructed stations; similar to a round of OSCE examination. Each team had $11 \mathrm{~min}$ in each station. There were 14 representative teams from provinces from all over Thailand participating in the rally. Each team had one physician, one nurse, and two emergency medicine technicians. Physicians acted as an instructor in the scene. Descriptions of the two CPR stations are described below.

Station no. 5 was an out-of-hospital cardiac arrest situation; instructed by the video (VDO) calls. Team members were trained how to use the VDO devices prior to entering the station. Physicians acted as online medical directors and were placed in another room. Physicians were able to order any treatment remotely. The connection between medical directors and team members was performed using Skype ${ }^{\oplus}$. Two smart phones and two tablets were used during the CPR in this station. One smart phone was connected with the defibrillator screen, while the other one captured the scene of the view from the feet of the patients for overview images. The medical director made any order via the tablets connected with smart phones from the distant center. Team members communicated to others by using bluetooth via smart phones. All connections used the $3 \mathrm{G}$ system. The physicians were able to view an overview of the scene, patient status, and electrocardiogram

Table 1 Characteristics of all participants categorized by occupations

\begin{tabular}{llll}
\hline Factors & $\begin{array}{l}\text { Physicians } \\
n=14\end{array}$ & $\begin{array}{l}\text { Nurses } \\
n=14\end{array}$ & $\begin{array}{l}\text { EMT } \\
n=28\end{array}$ \\
\hline $\begin{array}{l}\text { Mean age } \pm \text { SD, years } \\
\text { Age range, years }\end{array}$ & $27.64 \pm 2.56$ & $30.64 \pm 4.29$ & $29.68 \pm 7.013$ \\
$\begin{array}{l}\text { Gender } \\
\quad \text { Male }\end{array}$ & $25-34$ & $26-39$ & $20-49$ \\
& $7(50)$ & $6(42.9)$ & $23(82.1)$
\end{tabular}

Experiences in

ambulance, years

\begin{tabular}{|c|c|c|c|}
\hline$<1$ year & $6(42.8)$ & $0(0)$ & $0(0)$ \\
\hline $1-3$ years & $3(21.4)$ & $2(14.3)$ & $8(28.6)$ \\
\hline$>3$ years & $1(7.1)$ & $9(64.3)$ & $15(53.6)$ \\
\hline Not answered & $4(28.6)$ & $3(21.4)$ & $5(17.9)$ \\
\hline \multicolumn{4}{|l|}{ CLS certified, years } \\
\hline$<1$ year & $6(42.8)$ & $2(14.3)$ & $5(17.9)$ \\
\hline $1-3$ years & $4(28.6)$ & $6(42.9)$ & $10(35.7)$ \\
\hline$>3$ years & $1(7.1)$ & $3(21.4)$ & $3(10.7)$ \\
\hline Not answered & $3(21.4)$ & $3(21.4)$ & $10(35.7)$ \\
\hline \multicolumn{4}{|l|}{ S certified, years } \\
\hline$<1$ year & $6(42.8)$ & $1(7.1)$ & $3(10.7)$ \\
\hline $1-3$ years & $1(7.1)$ & $3(21.4)$ & $12(42.9)$ \\
\hline$>3$ years & $2(14.3)$ & $4(28.6)$ & $3(10.7)$ \\
\hline Not answered & $5(35.7)$ & $6(42.9)$ & $10(35.7)$ \\
\hline \multicolumn{4}{|c|}{ xperiences in CPR, year } \\
\hline$<1$ year & $3(21.4)$ & $4(28.6)$ & $5(17.9)$ \\
\hline $1-3$ years & $4(28.6)$ & $1(7.1)$ & $4(14.3)$ \\
\hline$>3$ years & $3(21.4)$ & $5(35.7)$ & $9(32.1)$ \\
\hline Not answered & $4(28.6)$ & $4(28.6)$ & $10(35.7)$ \\
\hline UT certified, years & NA & NA & \\
\hline$<1$ year & & & $2(7.1)$ \\
\hline $1-3$ years & & & $6(21.4)$ \\
\hline$>3$ years & & & $3(10.7)$ \\
\hline Not answered & & & $17(60.7)$ \\
\hline
\end{tabular}

Note. Data presented as numbers (percentage) unless indicated otherwise; $E M T$ emergency medicine technician, ACLS advanced cardiac life support, BLS basic cardiac life support, CPR cardiopulmonary resuscitation, NA not available 
(EKG) waves from the defibrillator, and to make treatment orders.

The scenario for this station was a 58 years old man with history of chest pain and loss of consciousness. The EKG was set to be pulseless ventricular tachycardia (VT) during the first six minutes, pulseless electrical activity (PEA) during the $6^{\text {th }}-8^{\text {th }}$ minutes, and return of spontaneous circulation (ROSC) until the end of station.

Station 11 had an on-scene medical director. The physician directed the situation onsite with other team members. The scenario was similar to the station no. 5 except the ECG for the first six minutes was ventricular fibrillation instead of VT. The Appendix shows example pictures of both stations.

Both stations were videotaped and outcomes were evaluated for each team. There were eight outcomes measured during the CPR including

1. Time from start to chest compression in seconds.

2. Time from start to VT/ventricular fibrillation (VF) detection correctly in seconds.

3. Time from VT/VF detection to the first defibrillation in seconds.

4. Time from start to adrenaline injection in seconds.

5. Treatment with amiodarone (yes/no).

6. Treatment to establish a definite airway using such as endotracheal tube, laryngeal mask airway, or Esophageal-Tracheal Combitube (yes/no).

7. High-quality CPR defined as three of these following items [6]

a. No interruption of chest compression or chest compression/total time of CPR of more than $80 \%$.

b. 100-120/min chest compression.

c. Avoidance of excessive ventilation by having assisted respiratory rate less than 12 times/minutes.

8. Correct detection of PEA (yes/no).

\section{Statistical analyses}

The outcomes of the online group were compared with the on-scene group. Time to event outcomes were calculated and presented as median values with $95 \%$ confidence intervals (CI) and Kaplan Meier curves. The Kaplan Meier curves of both groups were compared by the log rank test.
Cox regression analysis was used to demonstrate the strength of associations between the outcomes and groups by the hazard ratios. The categorical outcomes are described as numbers and percentages and the differences between groups compared by using the Mc Nemar's test for dependent proportion comparisons. All statistical analyses were performed by using the STATA software (College Station, Texas, USA).

\section{Results}

There were 14 representative teams who participated in the study that was comprised of a total of 14 physicians, 14 nurses, and 28 emergency medicine technicians. Characteristics of each type of participant are shown in Table 1 . The average ages of participants of all three occupations were between the second and third decades of life. The percentage of participants with more than 3 years experience in ambulance medicine was 7.1, 64.3, and $53.6 \%$ in the physicians, nurses, and EMTs groups as shown in Table 1.

The median times of all outcomes were significantly longer in the online group than on-scene group (Table 2) including total times from start to chest compression (102 vs 36 s), times from start to VT/VF detection (187 vs $99 \mathrm{~s}$ ); times from VT/VF detection to the first defibrillation ( 57 vs $28 \mathrm{~s}$ ); and times from start to adrenaline injection (282 vs 165 s). Kaplan-Meier curves of times from start to chest compressions are shown in Fig. 1.

The percentages of using amiodarone $(21.43 \%$ vs $57.14 \%$; $p$ value $<0.001$ ), establishment of a definitive airway (35.71 \% vs $100 \%$; $p$ value 0.003 ), and correct detections of PEA $(28.57 \%$ vs $100 \%$; $p$ value $<0.001)$ were significantly lower in the online group than in the onscene group (Table 3 ). The high quality CPR outcomes between the online group and on-scene group were comparable (Table 3).

\section{Discussion}

This study showed that the online medical instruction via VDO call was less effective compared with the on-scene medical instruction for the CPR simulated stations. All outcomes except the factors for the high quality CPR were significantly worse in the online group (Tables 2 and 3).

Table 2 Showed median times of CPR outcomes between an online medical command versus on-scene medical command

\begin{tabular}{lllll}
\hline Outcomes & Median time, seconds & HR & \multirow{2}{*}{$p^{*}$} \\
\cline { 2 - 3 } & Online medical command & On-scene medical command & \\
\hline Time from start to chest compression & $102(95 \% \mathrm{Cl} 56,132)$ & $36(95 \% \mathrm{Cl}: 27,50)$ & $3.98(95 \% \mathrm{Cl}: 1.61,9.87)$ & 0.002 \\
Time from start to VTNF detection & $187(95 \% \mathrm{Cl}: 106,239)$ & $99(95 \% \mathrm{Cl}: 77,128)$ & $9.64(95 \% \mathrm{Cl}: 2.58,35.99)$ & $<0.001$ \\
Time from VTNF detection to the first defibrillation & $57(95 \% \mathrm{Cl}: 35,107)$ & $28(95 \% \mathrm{Cl}: 15,39)$ & $2.84(95 \% \mathrm{Cl}: 1.15,7.01)$ & 0.017 \\
Time from start to adrenaline injection & $282(95 \% \mathrm{Cl}: 226,390)$ & $165(95 \% \mathrm{Cl}: 136,238)$ & $9.81(95 \% \mathrm{Cl} 2.7,35,66)$ & $<0.001$ \\
\hline
\end{tabular}

Note. $C P R$, cardiopulmonary resuscitation, $H R$ hazard ratio by the Cox regression analysis; $V T$ ventricular tachycardia, $V F$ ventricular fibrillation ${ }^{*} p$ value of log rank test 


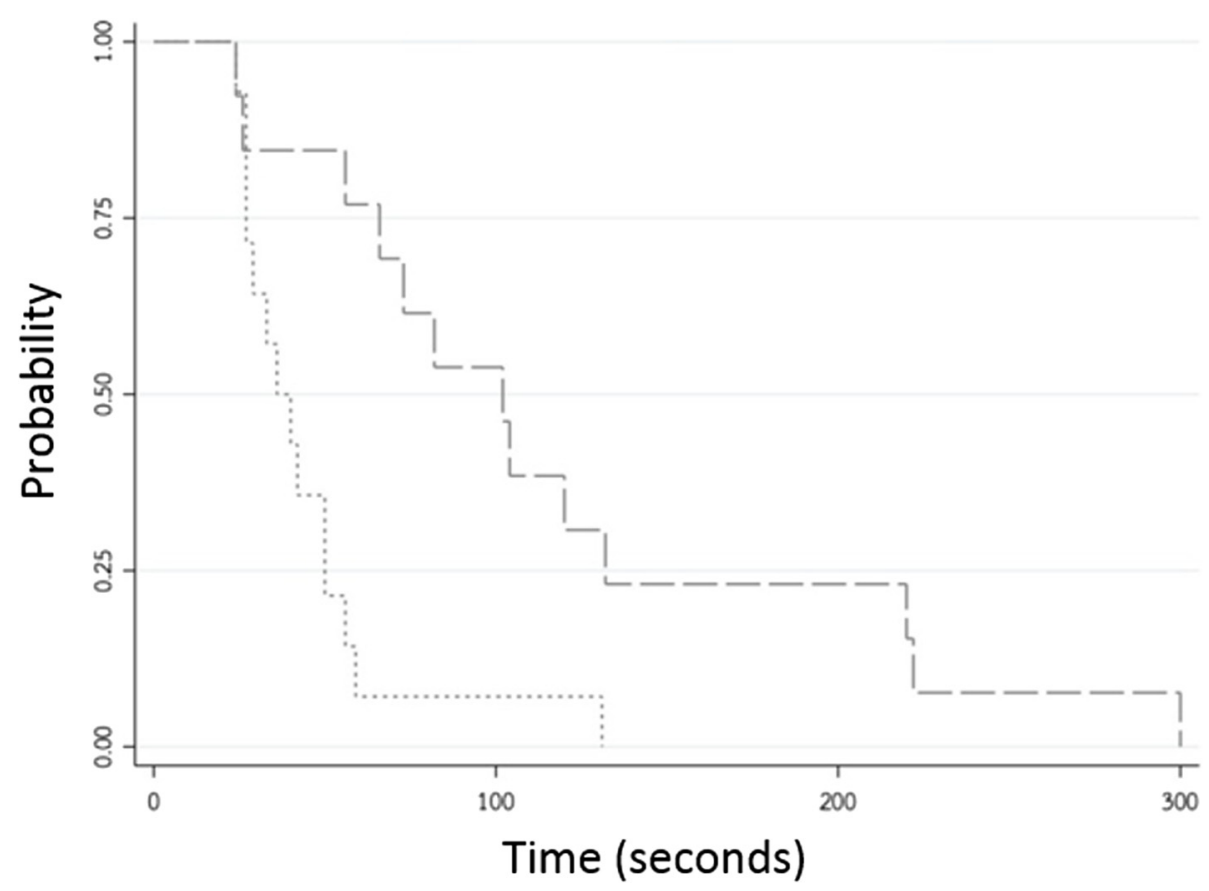

Fig. 1 Kaplan-Meier curve of time from start to chest compression between an online medical command (.......) and on-scence medical command (- - ) group

Note that these findings were based on the 14 teams who participated in two simulated shockable scenarios.

Previous studies showed that using video or real time telemedicine may improve CPR procedures $[6,7,9,10]$ particularly in CPR performance. Chest compression rates and depth were better with video instruction compared with the without cell phone video assist station (rates of $95.5 \mathrm{vs} 63.0 / \mathrm{min}$ and depth of 36.0 vs $25.0 \mathrm{~mm} ; p<0.01$ for both factors) [6]. Breathing was also better by adding video from cell phones during CPR [9]. The airways were wider open with the video assist group than the controls (95.3\% vs $58.5 \% ; p<0.01)$. There were limited more favorable outcomes of the CPR for the video assisted group. The results of this study indicated that the video assisted CPR may not have favorable outcomes; mainly due to correct detection of PEA (Table 3).
There are several explanations why the online medical command group did not have good CPR outcomes. Participants in the study were informed about the online system and tools only one minute prior to the test station (Station 5). They may not have been familiar with the online system and how to make a decision; this may have delayed the treatment and also assessment of the patient status. One striking finding is the proportion of correct detections of PEA. The online group correctly identified PEA in only five teams $(28.57 \%)$, while PEA was correctly detected in all teams with on-scene medical instruction (Table 3). This finding may result in low percentage of airway management and CPR outcomes. Clinical recognition on-scene may be more realistic than the online method. Also, note that a physician was not present in the online method. Communication between the physicians and

Table 3 Showed additional CPR outcomes between an online medical command versus on-scene medical command

\begin{tabular}{|c|c|c|c|}
\hline \multirow[t]{2}{*}{ Factors } & \multicolumn{2}{|l|}{ Numbers of team } & \multirow[t]{2}{*}{$p^{*}$} \\
\hline & $\begin{array}{l}\text { Online medical command } \\
n=14\end{array}$ & $\begin{array}{l}\text { On-scene medical command } \\
n=14\end{array}$ & \\
\hline Amiodarone treatment & $3(21.43 \%)$ & $8(57.14 \%)$ & $<0.001$ \\
\hline Treatment with definite airway & 5 (35.71\%) & $14(100 \%)$ & 0.003 \\
\hline No interrupt chest compression & $11(78.57 \%)$ & $13(92.86 \%)$ & 0.280 \\
\hline 100-120/min chest compression & $12(85.71 \%)$ & $13(92.86 \%)$ & 0.541 \\
\hline $12 /$ min assisted ventilation & $12(85.71 \%)$ & $13(92.86 \%)$ & 0.999 \\
\hline Correctly detection of PEA & $4(28.57 \%)$ & $14(100 \%)$ & $<0.001$ \\
\hline
\end{tabular}

Note. $C P R$ cardiopulmonary resuscitation, $H R$ hazard ratio by the Cox regression analysis, PEA pulseless electrical activity * $p$ value of Mc Nemar's test 
team members at the scene in the online command group may also be delayed because they needed to communicate via cell phone, while physicians and team members communicated to others immediately in the on-scene group.

The strength of this study is the evaluation of the CPR outcomes in online medical instruction via video calls from the 3G mobile system. These outcomes are limited in the literature which showed only CPR procedures $[6,7,9,10]$. Some study limitations exist. The study was not a randomized controlled trial due to station rotation sequences. Half of the 14 teams experienced the online type first, while the other half teams experienced the on-scene first. Secondly, the CPR scenarios were limited only to two shockable cases. Thirdly, data regarding CPR experiences were not obtained from all participants. Approximately $70 \%$ of participants, however, provided this information. Finally, the participants were not familiar with the online system. Technical errors and frustration may have occurred resulting in missing or giving the wrong treatment. Further studies with a randomized controlled trial and rigorous online pretraining should be performed.

\section{Conclusion}

Online medical instruction may have worse CPR outcomes compared with on-scene medical instruction in shockable CPR scenarios.

\section{Appendix}

A Online instructed station.

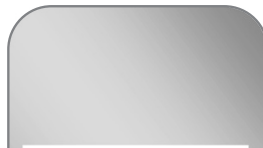

Commander
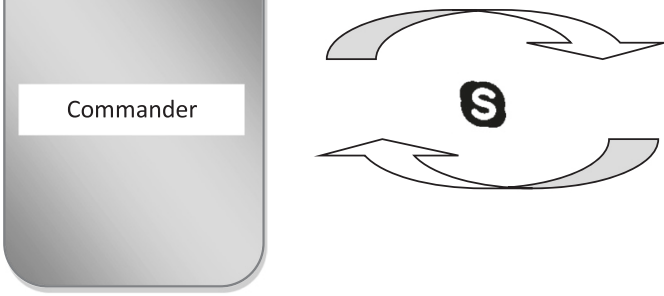

$\boldsymbol{S}$

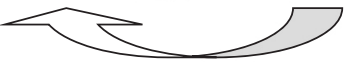

B On-scene instruction station.
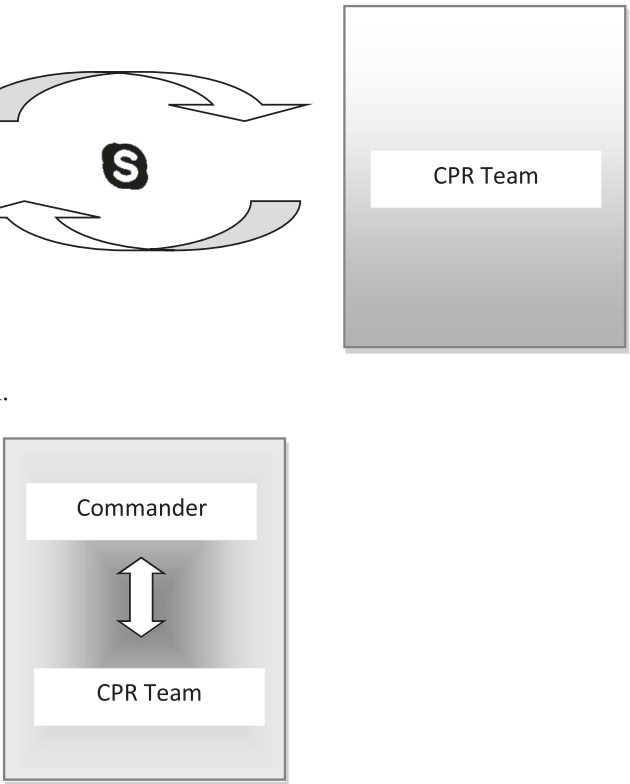

Fig. 2 Scheme of the cardiopulmonary resuscitation stations both online (a) and on-scene (b) instruction 


\section{Abbreviations}

ACLS, advanced cardiac life support; BLS, basic life support; $\mathrm{Cl}$, confidence intervals; CPR, cardiopulmonary resuscitation; EKG, electrocardiogram; PEA, pulseless electrical activity; ROSC, return of spontaneous circulation; VDO, video; VF, ventricular fibrillation; VT, ventricular tachycardia

\section{Acknowledgement}

The authors would like to thank all participants in the 2014 EMS rally and Prof. James A Will for his kind manuscript English editing via Publication Clinic KKU, Thailand. This study was supported by TRF Senior Research Scholar Grant from the Thailand Research Fund (TRF grant number RTA5880001), and the Higher Education Research Promotion and National Research University Project of Thailand, Office of the Higher Education Commission, Thailand, through the Health Cluster (SHeP-GMS), Khon Kaen University and Thailand Research Fund (IRG 5780016)

\section{Funding}

None.

\section{Availability of data and materials}

Data are available at: https://drive.google.com/folderview?id=0B2LtzgRY-puD NThrVURMWEY1TFk\&usp=sharing.

\section{Authors' contributions}

CY, SS, and YS conceived of the study and participated in its design. All authors participated in the interpretation of results and manuscript drafting or critical review. All authors read and approved the final manuscript.

\section{Competing interests}

The authors declare that they have no competing interests.

\section{Consent for publication}

Not applicable.

\section{Ethics approval and consent to participate}

The study protocol was approved by the ethical clearance committee on human rights related to research involving human subjects, Faculty of Medicine, Ramathibodi Hospital, Mahidol University (MURA2015/02). Informed consent was not required due to the retrospective nature of the study.

\section{Financial support}

None.

\section{Author details}

'Department of Emergency Medicine, Faculty of Medicine, Ramathibod Hospital, Mahidol University, Bangkok 10400, Thailand. ${ }^{2}$ Department of Medicine, Faculty of Medicine, Khon Kaen University, Khon Kaen 40002, Thailand. ${ }^{3}$ The Research Center in Back, Neck Other Joint Pain and Human Performance (BNOJPH), Khon Kaen University, Khon Kaen 40002, Thailand.

Received: 29 November 2015 Accepted: 7 June 2016

Published online: 12 July 2016

\section{References}

1. Meaney PA, Bobrow BJ, Mancini ME, et al. Cardiopulmonary resuscitation quality: [corrected] improving cardiac resuscitation outcomes both inside and outside the hospital: a consensus statement from the American Heart Association. Circulation. 2013;128:417-35.

2. Blanchard IE, Doig CJ, Hagel BE, et al. Emergency Medical Services Response Time and Mortality in an Urban Setting. Prehosp Emerg Care. 2012;16:142-51.

3. Eisenberg MS, Bergner L, Hallstrom A. Cardiac resuscitation in the community. Importance of rapid provision and implications for program planning. JAMA. 1979;241:1905-7.

4. American Heart Association Emergency Cardiovascular Care Committee 2010 American Heart Association guidelines for cardiopulmonary resuscitation and emergency cardiovascular care. Circulation. 2010;122: S639-946

5. Eisenberg MS, Hallstrom AP, Carter WB, Cummins RO, Bergner L, Pierce J. Emergency CPR instruction via telephone. Am J Public Health. 1985;75:47-50.
6. Johnsen E, Bolle SR. To see or not to see-better dispatcher-assisted CPR with video-calls? A qualitative study based on simulated trials. Resuscitation. 2008;78:320-6

7. Yang $\mathrm{CW}$, Wang $\mathrm{HC}$, Chiang WC, et al. Interactive video instruction improves the quality of dispatcher-assisted chest compression-only cardiopulmonary resuscitation in simulated cardiac arrests. Crit Care Med. 2009;37:490-5.

8. Rörtgen D, Bergrath $S$, Rossaint $R$, et al. Comparison of physician staffed emergency teams with paramedic teams assisted by telemedicine a randomized, controlled simulation study. Resuscitation. 2013;84:85-92.

9. Yang CW, Wang HC, Chiang WC, et al. Impact of adding video communication to dispatch instructions on the quality of rescue breathing in simulated cardiac arrests-a randomized controlled study. Resuscitation. 2008;78:327-32

10. Lee JS, Jeon WC, Ahn JH, Cho YJ, Jung YS, Kim GW. The effect of a cellularphone video demonstration to improve the quality of dispatcher-assisted chest compression-only cardiopulmonary resuscitation as compared with audio coaching. Resuscitation. 2011;82:64-8.

\section{Submit your next manuscript to BioMed Central and we will help you at every step:}

- We accept pre-submission inquiries

- Our selector tool helps you to find the most relevant journal

- We provide round the clock customer support

- Convenient online submission

- Thorough peer review

- Inclusion in PubMed and all major indexing services

- Maximum visibility for your research

Submit your manuscript at www.biomedcentral.com/submit
C Biomed Central 